\title{
CLASSROOM COMMUNICATION AND ICT INTEGRATION: PUBLIC HIGH SCHOOL TEACHERS' NOTIONS
}

\author{
Louis Placido Francisco Lachica \\ College of Education, Arts and Sciences, \\ Capiz State University Pontevedra Campus \\ Pontevedra, Capiz, Philippines
}

\begin{abstract}
As part of the $21^{\text {st }}$ Century skills, the integration of Information and Communication Technology is inevitable in classroom communication. This descriptive qualitative research covered all 60 teachers in five selected public high schools in Capiz, Philippines. Semi-structured interviews, informal interviews, and observations were done to gather data. The data were analyzed using General Inductive Approach and thematic analysis to unearth and cull emerging notions and themes. Participants viewed classroom communication as a process, tool, context, interaction, and strategy. ICT for them was a driver for change, a conduit for learning, a modern technology, and an instrument for effective teaching and learning. ICT integration in classroom communication was interpreted to have helped teaching, to be a new medium of instruction, and a marriage or partnership between classroom communication and ICTs. It is recommended that best practices in integrating ICTs in classroom communication should be explored and documented.
\end{abstract}

\section{KEYWORDS}

Classroom Communication, ICTs, ICT Integration, Notions

\section{INTRODUCTION}

The world is becoming challenged and interlinked due to the continuous advancements in the human society. In the changing global technological landscape, what compounds the difficulty in anticipating technological evolution is not just a lack of understanding of the technology per se which in itself is a formidable question given the speed of change in Information Technology but also the fact that what is possible does not always come to pass, and what comes to pass may scarcely seem possible. Society ultimately chooses which among all potential evolutions will become real by deciding where to invest and what to accept, adopt or reject (Gallaire, 2014).

The ability to use modern technology is essential in preparing people for competition in a global workplace (Brandenburg, 1998). Developing countries like the Philippines invest in ICT in education to decrease the social and intellectual inequalities among schools and their respective graduates (Coates, 1997). 
Essential to the depth of understanding of the integration of ICTs in classroom communication were the views of different stakeholders regarding how classroom communication should occur, what ICT tools must be utilized, and what teaching-learning system should be applied. Integrating ICTs in classroom communication does not simply end with providing necessary technological infrastructure, employing teaching and learning strategies, and participating in social interaction. It is also important to give voice to the end users about their perceived benefits from utilizing ICTs in classroom communication. Likewise, basic and technical pitfalls hampering successful integration of ICTs should be identified. This serves as a feedback to planners and implementers of future initiatives along this line to further improve the interventions.

\section{NOTIONS OF CLASSROOM COMMUNICATION, ICTS, AND ICT INTEGRATION}

The teachers' notions of classroom communication, ICTs, and ICT integration are essential to the understanding of its relevance to the teaching-learning process. Thus, these salient points were considered in this study.

\subsection{Theoretical Background and Brief Literature}

This study is anchored on the Instructional Technology Diffusion Theory, specifically Technological Instrumentalism and Technological Determinism, and Constructivism.

Surry (1997) developed the Instructional Technology Diffusion Theory. He defined diffusion as the process by which an innovation is adopted, and gains acceptance by members of a certain community. He believes that instructional technologists must be able to understand the factors that influence adoption of innovation as well as the innovation process and theories of innovation diffusion to be able to work effectively with potential adopters. Each category can still be divided into two subcategories representing two predominant philosophies of technology and technological change: Technological Determinism and Technological Instrumentalism.

Technological determinists view technology as an autonomous force beyond direct human control, and see technology as the prime cause of social change (Chandler, 1995 as cited by Surry, 1997 and Alagaran, 2009). This underlying assumption adheres to the belief that superior technological products and systems will, by virtue of their superiority alone, replace inferior products and systems. Determinists see change as following directly from a technological revolution (Alagaran, 2009).

Technological instrumentalists, on the other hand, view technology as a tool, largely under human control, that can be used for either positive or negative purposes. Instrumentalists also see social conditions and human aspirations as the primary causes of change. The focus is on the human and interpersonal aspects of innovation diffusion. Adopter-based theories are inherently instrumental in philosophy because they view the end user - the individual who will ultimately implement the innovation in a practical setting, as the primary force for change (Surry, 1997 as cited by Alagaran, 2009).

Technological superiority alone is not enough to guarantee the adoption of an innovation. Adopting new instructional technologies is not automatic since the potential adopters need to understand the social context in which the innovation will be used (Surry, 1997 as cited by Alagaran, 2009). 
A theory developed by Jesse Delia and his colleagues, constructivism explains that individuals interpret and act according to conceptual categories in the mind (Littlejohn, 2008). Vygotsky, Piaget, Dewey, Vico, Rorty, and Bruner were originators and important contributors to constructivism as a learning theory. Constructivism as a paradigm or worldview posits that learning is an active, constructive process. The learner is an information constructor. People actively construct or create their own subjective representations of objective reality. New information is linked to prior knowledge, thus mental representations are subjective. Learning is an active, contextualized process of constructing knowledge rather than acquiring it. Knowledge is constructed based on personal experiences and hypotheses of the environment. Learners continuously test these hypotheses through social negotiation. Each person has a different interpretation and construction of knowledge process. The learner is not a blank slate (tabula rasa), but he brings past experiences and cultural factors to a situation. Constructivism is associated with learning as experience, activity and dialogical process, Problem-Based Learning (PBL), Anchored Instruction, Vygotsky's Zone of Proximal Development (ZPD), Cognitive Apprenticeship (scaffolding), and Inquiry and Discovery Learning (www.learning-theories.com, 2013).

\subsection{Methodology}

The study was done at five iSchools Project beneficiary public high schools located in upland and coastal areas in the province of Capiz. All 60 teachers taken in complete enumeration served as participants.

Data for this study were obtained through semi-structured interviews, informal interviews, and observations. The interviews were done by requesting the participants to write their notions on classroom communication, ICTs, and ICT integration.

The data gathered were analyzed qualitatively. The General Inductive Approach was used to analyze the transcribed texts. The dominant emerging themes were culled from the transcripts using thematic analysis.

\subsection{Highlights of Findings and Discussion}

This study attempts to describe and analyze the notions of public high school teachers' about classroom communication, ICTs, and ICT integration.

\section{3.a.Notions of Classroom Communication}

Classroom communication is reflected in the statements provided by the public high school teachers in selected iSchools Project beneficiary schools in the rural communities in the province of Capiz.

The statements suggest that the participants look at classroom communication as a process, an interaction, and a tool. They also consider it as a medium for effective teaching-learning process, a strategy, and a place and/or situation. Specifically, teachers from both coastal and upland public secondary schools view classroom communication as a process. In coastal rural schools, teachers considered it as a form of interaction and as a strategy. It is also considered as a tool or medium for teachers in both upland and coastal public secondary schools. According to teachers from upland public secondary schools, classroom communication can be a place or situation where interaction takes place. 
Dominant themes that emerged from the statements of the teacher-participants are detailed in Table 1. These themes provide an account of their perceptions about classroom communication and can be narrowed down into dynamic and static view.

Table 1. Emerging themes on Classroom Communication

\begin{tabular}{|l|c|c|}
\hline \multirow{2}{*}{ Notions } & \multicolumn{2}{|c|}{ Public Secondary Schools } \\
\cline { 2 - 3 } & Coastal & Upland \\
\hline A. Dynamic & & \\
\hline Process & $\sqrt{ }$ & \\
\hline Interaction & $\sqrt{ }$ & \\
\hline Interaction & $\sqrt{ }$ & \\
\hline Strategy & $\sqrt{ }$ & \\
\hline B. Static & $\sqrt{ }$ & $\sqrt{ }$ \\
\hline Tool/Medium & & $\sqrt{ }$ \\
\hline Context & & \\
\hline
\end{tabular}

The following explanations present the perceptions on classroom communication of the public secondary school teachers. These were gathered from their statements. According to them, classroom communication can be a process of transferring knowledge and information to the learners. These were reflected on the following exemplars:

Classroom communication is a process wherein teachers and students create and cocreate knowledge together.

Classroom communication is a process encompassing teaching and learning in the classroom. It predominantly takes place through interpersonal communication between teachers and students. It is constructed by the teacher and students. It is negotiated by them.

The above statements of public secondary school teachers emphasize that classroom communication is a dynamic process. It is in this process that knowledge is being created and cocreated between the teacher and the students. Classroom communication encompasses another process which is the teaching-learning process. It is in the context of the teaching-learning process where classroom communication occurs. This process is predominantly interpersonal in nature. Communication is negotiated by actors in the process. It becomes effective when both actors are active participants as knowledge sharing takes place.

The accounts of the public secondary school teachers reveal that classroom communication serves as a tool or instrument for learning as shown below:

Classroom communication is a tool that highly affects learning to take place and which greatly influences how a teacher would be able to catch attention of students in such a way that learning can be transmitted from the teacher towards the learners and vice versa.

Classroom communication is the medium that we use to communicate to our students. It can be posters, bulletin boards, books, other reading materials, videos, Powerpoint presentations, and verbal communication or interactions which are usually practiced by teachers to relay information. 
The teacher-participants perceive classroom communication as a tool that affects learning. It may influence teachers to encourage students to focus in order for learning to take place. As a medium, classroom communication comes in the form of instructional, educational, and communication materials (IEC) to relay information. Through classroom communication, transmission of learning from the teacher to the students occurs.

Based on the statements of the public secondary school teachers, classroom communication refers to interaction.

Classroom communication is the interaction dealing with the creation of knowledge between the teacher and the students and among students. This happens in series of pervasive educational exchanges and dialogues within the classroom.

Data sources show that classroom communication is done through the interaction between teachers and students. This interaction occurs with a well-defined understanding of what will transpire in the teaching-learning process. They believe that through classroom communication, the teacher's impact widens not only inside the classroom to the students but also in the community. It is through classroom communication that knowledge creation happens among the actors through pervasive educational exchanges and dialogues.

Interaction occurs in a particular place and in a specific situation. It is apparent from the preceding statements that classroom communication is brought about in a place or situation.

Classroom communication is a place where learning interaction takes place, communication inside the classroom consist of ideas, opinions and medium of instruction.

Classroom communication is a situation wherein students and teachers interact and exchange ideas on each other.

Humans communicate across time, space, and context. Data sources convey that classroom communication is a context. Context may refer to the environment in which communication takes place. The classroom is considered as the context of communication as pointed out by the teacher-participants. Teaching and learning takes place and can be shaped through classroom communication

Based on the statements of the public secondary school teachers, classroom communication is a strategy. Closely linked to the teaching-learning process, classroom communication brings into reality a desired end of a particular goal.

Classroom communication is an effective strategy that can get students out of "tell me" and "show me" attitude into a lively and actively participating students during the teaching-learning process.

It can be a strategy to deliver education effectively through communication.

These statements suggest the idea of moving beyond the traditional classroom setting wherein students are considered as passive and muted learners. As a strategy, classroom communication promotes participation of the learners. Participation enhances the interest of the learners by providing an avenue for dialogue among and between students. It engages them to think critically. 


\section{3.b.Views of Information and Communication Technology}

Perceptions on information and communication technology were reflected on the statements of the public secondary school teachers. Table 2 presents the dominant themes on Information and Communication Technology that came out from the statements of the teacher-participants of this study.

Table 2. Emerging themes on Information and Communication Technology

\begin{tabular}{|l|c|c|}
\hline \multirow{2}{*}{\multicolumn{1}{|c|}{ Notions }} & \multicolumn{2}{c|}{ Public Secondary Schools } \\
\cline { 2 - 3 } & Coastal & Upland \\
\hline Driver for Change & $\sqrt{ }$ & \\
\hline Conduit/Channel & $\sqrt{ }$ & \\
\hline Modern Technology & $\sqrt{ }$ & $\sqrt{ }$ \\
\hline Tool & $\sqrt{ }$ & $\sqrt{ }$ \\
\hline
\end{tabular}

Public secondary school teachers from both coastal and upland areas considered ICTs a form of modern technology and as a tool. Teachers from coastal rural schools view ICTs a driver for change, a conduit for learning, and as an instrument utilized for teaching and learning.

The explanations below present the perceptions about ICTs which were taken from the statements of the teacher-participants of this study. The accounts of teachers highlight ICTs as leading the way to changes in classroom communication.

\section{I consider it as a driver for change. It allows efficient and effective use of knowledge and skills and answers current needs and opportunities expected for the so-called $21^{\text {st }}$ Century learners who are equipped with everything that is needed in a time where technology has been a part of life.}

This statement reveals that ICTs unravel significant technological breakthroughs. Technology, whether we like it or not, is a part of our everyday life. In classroom communication, ICTs are utilized to improve the way students learn and the way teachers' teach. As a driver for change, ICTs enable actors in classroom communication to cope with the needs and opportunities in the $21^{\text {st }}$ century. It brings about intellectual development through collaborative learning that promotes creative thinking and communication among learners. ICTs changed the way teachinglearning process is done. Teachers are no longer considered as the ultimate source of knowledge but rather as facilitators of the creation of knowledge and skills. Through ICTs, students transformed from passive receivers of knowledge and information into active learners. Thus, the teaching-learning process now is more student-centered.

The ICTs that are utilized in the public high schools covered in this study are desktop computer, laptop, LCD projector, television, and radio. It can be noted that ICTs can be a channel for facilitating learning and in performing the teaching process. This can be seen on the followings statements of the teacher-participants:

ICT serves as a conduit or channel for delivering our lesson or to communicate to our students and to other people in a creative and desirable manner.

It is one of the most powerful channels between students and the teacher that makes learning better and more exciting and teaching highly improved. 
ICTs open up a lot of opportunities for improving the delivery of the lessons through classroom communication. This can be done in a more creative and desirable manner. The teacherparticipants stated that utilizing it promotes creative learning in their students. With the intervention of ICTs, being considered as a powerful channel for communication, the application of current trends in both creative learning and innovative teaching are possible.

One of the most important perceptions that surfaced from the statements of the teacherparticipants is that ICTs are instrumental to effective teaching and learning.

It is a tool where you can easily get more knowledge and also improve the sharing of ideas in the classroom. It develops and enhances the skills particularly to the student-teacher interaction. ICTs serve as tools for better generation of knowledge and information. For example, the use of LED monitor and computers further provides a vivid illustration of the topic being explained by the teacher.

ICT is a tool used by educators to enhance communication and to bolster learning activities.

Statements reveal that ICTs are salient instruments for teaching and learning. ICTs enhance sharing and interaction. According to a teacher-participant, the use of LED screen or projector provides a vivid illustration and explanation of the lesson during class discussion. In a way, it raises the students' curiosity for better understanding and appreciation of the lessons. ICTs also facilitate the acquisition of knowledge and information. The teachers observed that this helped in developing the students' critical thinking skills.

The statements of the teacher-participants reveal that ICTs, as products of innovations in technology, are setting the trend towards development specifically in classroom communication.

It is using the technology to gather, share, and communicate with others easily. It is an innovation that brings forth development. It is like stepping outside of the box and doing things beyond the usual.

ICT is an innovation that would allow efficient and effective use of knowledge and skills to easier current needs and opportunities. This is needed especially in a school like ours, which is very remote.

The statements of teacher-participants disclose that ICTs are important breakthroughs in technology wherein the latest information can be generated through its integration. It can also be used in gathering, sharing, and communicating with others quickly. Through ICTs, the transfer of knowledge and information becomes fast. ICTs link up to real world in real time. It can tap experts, and help in visualizing data. Timely feedback can be taken from ICTs. It also serves as a tool for analyzing. All these advantages of ICTs viewed as a form of modern technology surfaced from the statements of the public secondary school teachers.

\section{3c.Views of ICTs in Classroom Communication}

Statements of teacher-participants explain further perceptions of ICTs in classroom communication. 
Table 3 shows the emerging themes on ICT integration in classroom communication gathered from the statements of public secondary school teachers from the five iSchools Project beneficiary schools in the province of Capiz. The interplay of ICTs in classroom communication is viewed to have helped in teaching according to public secondary school teachers from the five iSchools Project beneficiary schools.

Table 3. Emerging themes on ICT Integration in Classroom Communication

\begin{tabular}{|l|c|c|}
\hline \multirow{2}{*}{\multicolumn{1}{|c|}{ Notions }} & \multicolumn{2}{c|}{ Public Secondary Schools } \\
\cline { 2 - 3 } & Coastal & Upland \\
\hline Helps in Teaching & $\sqrt{ }$ & $\sqrt{ }$ \\
\hline New Medium of Instruction & & $\sqrt{ }$ \\
\hline Marriage/Partnership & $\sqrt{ }$ & \\
\hline
\end{tabular}

The following statements detail how the public secondary school teachers perceive the integration of ICTs in classroom communication.

The statements of the teacher-participants show that ICT integration in classroom communication aids in teaching.

ICTs in classroom communication help and aid teachers in easily explaining complex lessons thereby ensuring students' comprehension, teachers are able to create interactive classes, and make the lessons more enjoyable which could improve student attendance and concentration.

ICTs in classroom communication help us to teach more effectively. I have observed that the presence of ICTs in our school, in a way, increased the interest of students to learn. Whenever ICTs are utilized in classroom communication, the focus of students on the lesson can be felt.

Data sources present that ICT integration in classroom communication aids in teaching, especially in explaining complex lessons. It ensures students' comprehension by creating interactive classes. The teacher-participants claim that it makes the teaching-learning process more enjoyable for students. The teachers also claimed that ICTs in classroom communication helps in teaching by enhancing the eagerness of students to actively participate in class. They also observed that it increased the interest of students to learn and focus more on the lessons.

The statements of the teacher-participants reveal that the integration of ICTs in classroom communication is the new medium of instruction.

ICT refers to the new medium of instruction, which uses modern technology as a tool to communicate with students for the delivery of knowledge and information. In a way, ICTs craft a new language which makes it a lot interesting among students.

I consider ICTs as the new medium of instruction because its integration crafts a new way of how classroom communication should be done. 
The above statements give details of the teachers' perception of why and how ICT integration in classroom communication can be considered as a new medium of instruction. This draws on the interest of students to use it as a tool. ICTs craft a new language through the retrieval of vast and diverse information that promotes the creation of new trends. It develops a new way of doing classroom communication by stirring the traditional classroom leading to a new system of making a more meaningful and improved learning experience.

It also became apparent from their statements that they consider ICT integration in classroom communication as a marriage or partnership based on these statements:

It is the marriage or perfect partnership of classroom instruction and the various forms of technology. These two should blend well to obtain desirable results. The weakness of one should be sufficed by the strength of the other one.

It is a partnership of traditional classroom teaching and the use of modern technology to better execute classroom communication which embraces the teaching-learning process. The advantages of both should be utilized for better results.

Data sources suggest that in order for ICT integration in classroom communication to work, traditional classroom teaching properly integrated with modern technology will lead to a better teaching and learning process. The strengths of utilizing ICTs should be combined with that of the traditional approaches in teaching and learning. It can also be implied that there should be a good balance of combining these for improved classroom communication.

\section{IMPLICATIONS}

Notions of classroom communication, ICTs, and ICT integration of the public high school teachers provided an opportunity to allow them to construct their realities. Constructions influence people's action and interaction. They help people interpret the world and thus act on the basis of such interpretation (Saludadez and Garcia, 2001 as cited by Ocampo, 2008). Meaning structures are interpretive schemes or frames, which are individual's schemes of making sense of the world. They are shared meaning systems about ways to approach and proceed in situations, and incorporate evaluative sentiments and stocks of knowledge. These structures act as a basis for actors' conceptual systems, the way they think, act, and perceive reality (Conlon, 1999 as cited by Saludadez and Garcia, 2001 and Ocampo, 2008).

The generation of qualitative findings from this study shows the context of ICT integration in classroom communication in public high schools under the iShools Project.

\section{RECOMMENDATIONS FOR FUTURE RESEARCH}

Deliberately in-depth studies on the nuances of possible recipients of projects or initiatives even at the planning stage of creating such projects should be done together with policymakers, planners, and project implementers. The elicitation of their views should be participatory. Both top-down and bottom-up approaches should be considered. Other methods of generating views from various stakeholders may also be utilized. The expertise of development communication practitioners, strategic planners, and policy analysts is direly needed. 
This study recommends that similar studies provide more empirical data through quantitative research that will serve as a benchmark for future initiatives and projects. Likewise, the study may convince the policymakers to support endeavors related to ICT integration in classroom communication. The best practices in integrating ICTs in classroom communication in the context of the iSchools Project beneficiary schools should be explored and documented.

\section{CONCLUSIONS}

From this study, classroom communication emerged as dynamic and static. It is viewed as a process, it involves interaction, and it could be a strategy. Classroom communication also serves as tool for learning to take place and as a context. How public secondary school teachers perceive classroom communication reflects the way they handle the transmission of knowledge and information.

Information and communication technology was viewed as a driver for change, a conduit or channel, a form of modern technology, and an instrument for effective teaching and learning. The divergent understanding of ICTs was due to its very pervasive presence in the society. Public secondary school teachers' concepts of ICTs may hold true as to its use either personally or professionally.

ICTs in classroom communication were interpreted to have helped in teaching, new medium of instruction, and marriage/partnership. The various features of ICT tools can help process knowledge and information exchange that support various activities in teaching and learning,

\section{REFERENCES}

[1] Alagaran, Jose Reuben (2009) In Keeping with the Digital Age: Planning and Adoption of ICT Among Communication Educators in the Philippines, Unpublished Dissertation. University of the Philippines Diliman.

[2] Asgarkhani, Mehdi and James, William (2008) "A Pilot Study of Current Trends in Information and Communication Technology (ICT) Education within the Tertiary Sector”, Contemporary Management Research 4: 291-304.

[3] Brandenburg, Marcus and Dudt, Kurt (1998) International Education, Accessed in curry.ateneo.net, Date accessed: June 16, 2015.

[4] Chowdhury, Mehdi (2009) "ICT Integration Trends and Practices in College Classrooms", EDULEARN09 Conference. pp. 48-59. Barcelona, Spain: Proquest.

[5] Creswell, John (2003) Research Design: Qualitative, Quantitative, and Mixed Methods Approaches $\left(2^{\text {nd }} e d.\right)$, California, U.S.A. SAGE Publications, Inc.

[6] Coates, Joseph (1997) The Nexy Twenty-Five Years of Technology: Opportunities and, Accessed in: www.oecd.org, Date accessed: June 8, 2015.

[7] de Guzman, Allan and Fabian, Federico (2008) "A Triad of Filipino Adolescents' Zones of Lived Experiences of Information and Communications Technology (ICT)," Educational Research Policy Practice. pp. 23-34.

[8] Gallaire, Herve (1998) $21^{\text {st }}$ Century Technologies: Promises and Perils of a Dynamic Future, Accessed in www.oecd.org, Date accessed: May 27, 2014.

[9] Lewin, Kurt (n.d.) Compare: A Journal of Comparative Education, Accessed in curry.ateneo.net, Date accessed: June 16, 2015.

[10] Littlejohn, Stephen and Foss, Karen (2009) Encyclopedia of Communication Theory, SAGE Publications, Inc., California, USA, pp. 66-65, 776-777, 978-979.

[11] Littlejohn, Stephen and Foss, Karen (2008) Theories of Human Communication, USA: Wadsworth Publishing Co. 
[12] Ocampo, Lalaine (2008) Classroom Communication as a Site of Empowerment and Marginalization in the Stories College Students Tell, Unpublished Doctoral Dissertation. University of the Philippines Los Baños.

[13] Saludadez, Jean and Garcia, Primo (2001) "Seeing pur Quantitative Counterparts: Construction of Qualitative Research in a Roundtable Discussion," Forum Qualitative Sozialforschung / Forum: Qualitative Social Research (Online Journal), 2 (1). Accessed from: http://qualitative research.net/fqs/fqs-eng.htm. Date accessed: October 28, 2013.

[14] Strauss, Anselm and Corbin, Juliet (1998) Basics of Qualitative Research (2nd ed.), USA, CA: Sage Publications.

[15] Teddlie, Charles and Tashakkori, Abbas (2003) "Major Issues and Controversies in the Use of Mixed Methods in the Social and Behavioral Studies," Handbook of Mixed Methods in Social and Behavioral Research, Thousand Oaks: Sage Publications.

[16] Tinio, Victoria (2005) National Framework Plan for ICTs in Basic Education (2005-2010), Makati City: Foundation for Information Technology in Education.

[17] Villamor, Ted (2011) "The Level of Implementation of Information and Communication Technology for Basic Education Program at Ligao City D ivision: An Assessment," International Journal of Arts and Sciences. pp. 363-386.

\section{Author}

Dr. Louis Placido F. Lachica graduated in 2001 with the degree Bachelor of Secondary Education major in English and his Master of Arts in English degree in 2008. In 2014, he finished his Doctor of Philosophy in Development Communication with cognate in Strategic Planning and Public Policy at the University of the Philippines Los Baños as a full scholar of the Commission on Higher Education Faculty Development Program Phase II (CHED FDP II). For

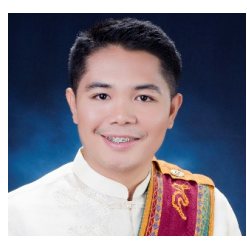
a decade now, he has been teaching at Capiz State University Pontevedra Campus. At present, he is the program coordinator of the Bachelor in Elementary Education in the same university. 